\title{
High-Cycle Fatigue of ULTIMET $®$ Alloy
}

\author{
L. Jiang, ${ }^{1}$ C. R. Brooks, ${ }^{1}$ P. K. Liaw, ${ }^{1}$ and D. L. Klarstrom ${ }^{2}$ \\ 1. Department of Materials Science and Engineering \\ The University of Tennessee Knoxville \\ Knoxville, TN 37996-2200 \\ 2. Haynes International, Inc. \\ Kokomo, IN 46904-9013
}

\begin{abstract}
ULTIMET $^{(3)}$ alloy, a relatively new commercial Co-26Cr-9Ni superalloy, was studied to examine its fatigue behavior at low and high frequencies and in different environments. The microstructure of the alloy in the solution-annealed condition consisted of face-centered-cubic, single phase, relatively fine, and uniform grains with annealing twins. Stress-controlled fatigue tests were performed at room temperature with an R-ratio (the ratio of the applied minimum stress to the maximum stress levels) of 0.05 . The high-frequency $(1,000 \mathrm{~Hz})$ high-cycle fatigue tests gave results comparable to the low-frequency $(20 \mathrm{~Hz})$ tests. Interestingly, there was a plateau region in the S-N (maximum applied stress level versus number of cycles to failure or run-out) curves of this alloy regardless of the testing frequencies and environments. At $20 \mathrm{~Hz}$, the maximum stress level of the plateau was around $600 \mathrm{MPa}$, which is approximately equal to the yield strength of $586 \mathrm{MPa}$, and at $1,000 \mathrm{~Hz}$ the plateau region occurred at $540 \mathrm{MPa}$. The microstructural characterization of tested specimens revealed that the evolution of stacking faults played an important role in the fatigue process. The results of fractographic studies indicated that cracking was initiated either on the specimen surface or subsurface depending on test conditions, and the crackinitiation sites were cleavage-like in nature, typical of stage I crack initiation. The presence of oxygen and/or moisture in the test environments was found to have significant effects on the fatigue-crack initiation behavior and fatigue life of ULITMET alloy. The fatigue-fracture surfaces were observed to have a crystallographic appearance for all of the conditions investigated.
\end{abstract}

\section{Introduction}

Fatigue-crack initiation and propagation have been identified as one of the critical areas in determining the safety, durability, and reliability of structural components. To our knowledge, little work has been done on the fatigue behavior of ULTIMET alloy. In the present work, fatigue-crack initiation and propagation characteristics of ULTIMET alloy were investigated.

The availability of fatigue data in ULTIMET alloy will provide new commercial opportunities. In addition, the systematic study of the effects of applied maximum stress levels, frequencies, and environments on the fatigue lives of ULTIMET alloy offers pertinent information for engineering applications. It also facilitates the understanding of fatigue-crack nucleation and propagation behavior in light of microstructural characterizations by $x$-ray diffraction, optical microscopy (OM), scanning electron microscopy (SEM), transmission electron microscopy (TEM), etc.

This paper presents the first comprehensive description of the high-cycle fatigue behavior of ULTIMET alloy tested at room temperature under two frequencies, $20 \mathrm{~Hz}$ and $1,000 \mathrm{~Hz}$, and various environments, including typical air with $20 \%$ to $24 \%$ relative humidity, 0 grade dry air with $0 \%$ relative humidity, and vacuum of $10^{-6}$ to $10^{-7}$ torr. Based on the S-N curves, the effects of environments and frequencies on fatigue life were examined.

Furthermore, subsurface crack-initiation sites were observed for ULTIMET alloy undergoing high-cycle fatigue. Internal fatiguecrack-initiation origins in most materials have invariably been associated with the presence of inclusions, but ULTIMET alloy is a "clean" material due to Argon-Oxygen Degassing (AOD) and Electric Slag Remelting (ESR) refining processes. Observations were made of the effect of environmental conditions and testing frequencies by microscopic techniques in order to understand the formation of internal fatigue-crack-initiation origins.

\section{Experimental}

\section{Material}

Wrought cobalt-based alloys including ULTIMET alloy provide excellent elevated-temperature strength, and resistance to various forms of wear and sulfidizing environments. ${ }^{[1-5]}$ The nominal chemical composition of ULTIMET alloy, developed by Haynes International, Inc., is shown in Table ${ }_{1 .}^{[6]}$ It possesses high tensile strength combined with excellent impact toughness and ductility. ${ }^{[6]}$ The typical room-temperature yield strength of the alloy plated tested was $586 \mathrm{MPa}$, the tensile strength was 1,000 $\mathrm{MPa}$, and the elongation was $39 \%$. ULTIMET alloy is an appropriate material for fabricating structural components, such as agitators, blenders, spray nozzles, screw conveyors, and valve parts.

Table I: Nominal Chemical Composition of ULTIMET Alloy (Weight Percent).

\begin{tabular}{|l|l|l|l|l|l|l|l|l|l|}
\hline $\mathrm{Co}$ & $\mathrm{Cr}$ & $\mathrm{Ni}$ & $\mathrm{Mo}$ & $\mathrm{Fe}$ & $\mathrm{W}$ & $\mathrm{Mn}$ & $\mathrm{Si}$ & $\mathrm{N}$ & $\mathrm{C}$ \\
\hline $54^{\mathrm{a}}$ & 26 & 9 & 5 & 3 & 2 & 0.8 & 0.3 & 0.08 & 0.06 \\
\hline
\end{tabular}

The element cobalt exhibits two crystallographic forms. Below $400{ }^{\circ} \mathrm{C}$, the stable structure is hexagonal-close-packed (HCP or $\varepsilon$ ); above this temperature, it is face-centered-cubic (FCC or $\gamma$ ), as shown in Figure $1 .^{[7]}$ This phase transformation makes cobalt a unique alloy base. ${ }^{[1]}$ For most of the cobalt-based alloys, the cooling rates from the solution annealing temperature are high enough to avoid the FCC to HCP transformation, and the lack of sufficient thermal energy prevents the transformation from occurring at room temperature. However, the transformation can be triggered at room temperature by mechanical deformation. For Co-27Cr-5Mo alloys, the FCC to HCP transformation can be easily triggered by mechanical deformation. ${ }^{[5,8]}$ Haynes 25 alloy, a
Superalloys 2000

Edited by T.M. Pollock, R.D. Kissinger, R.R. Bowman

K.A. Green, M. McLean, S. Olson, and J.J. Schirra

TMS (The Minerals, Metals \& Materials Society), 2000 
Co-20Cr-15W-10Ni alloy, can result in the FCC to HCP transformation by $20 \%$ cold reduction. ${ }^{[5,8]}$ For MP35N alloy, a Co$35 \mathrm{Ni}-20 \mathrm{Cr}-10 \mathrm{Mo}$ alloy, the stress (or strain) induced FCC to HCP transformation does not occur at room temperature, however, extensive twinning has been observed. ${ }^{[5,8]}$ Therefore, it is likely that ULTIMET alloy may undergo the $\gamma-\varepsilon$ transformation during fatigue testing.

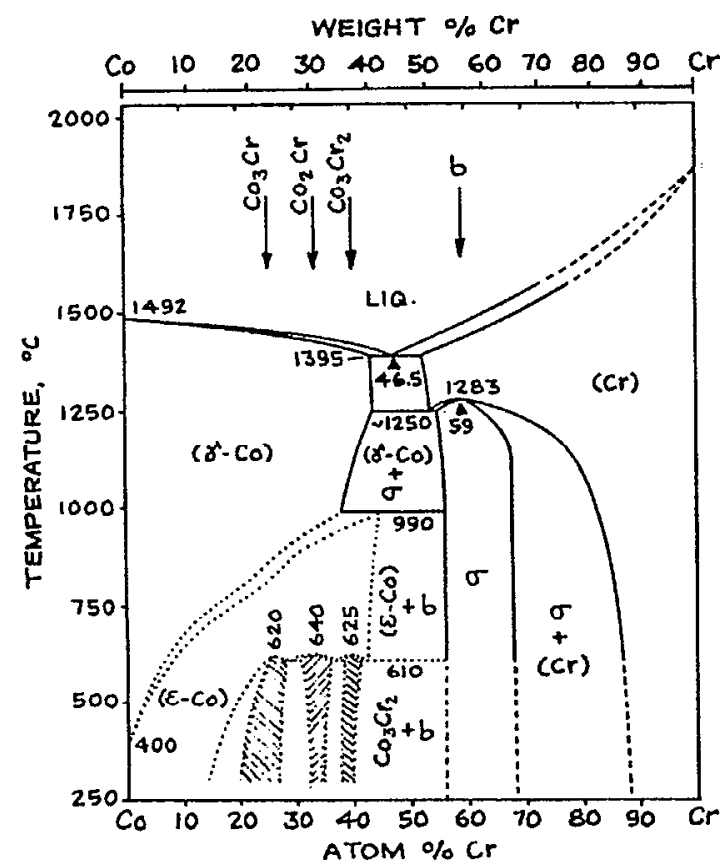

Figure 1: Cobalt-Chromium Binary Phase Diagram. ${ }^{\left[{ }^{7]}\right.}$

The specimens of ULTIMET alloy, used for high-cycle fatigue testing, were produced as follows: (a) Plate feedstock was reduced in thickness from $30.48 \mathrm{~cm}$ to $1.27 \mathrm{~cm}$ in a 4-pass, cross-rolling sequence at $1,200^{\circ} \mathrm{C}$, and (b) The material was solution-annealed at $1,120^{\circ} \mathrm{C}$ for about 20 to 30 minutes, then water-quenched to room temperature in order to retain the FCC structure.

\section{Fatigue Testing}

Uniaxial high-cycle fatigue tests were performed using smooth round-bar specimens. The test procedures were in accordance with the American Society for Testing and Materials (ASTM) E466 for "Conducting Constant Amplitude Axial Fatigue Tests of Metallic Materials." ${ }^{\text {[9] }}$ The gage section of the test specimens was $5.08 \mathrm{~mm}$ in diameter and $19.05 \mathrm{~mm}$ in length. The final polishing operation produced fine marks parallel to the longitudinal axis of the test specimen, and the surface finish of a surface roughness smaller than $0.2 \mu \mathrm{m}$ was in compliance with the ASTM standard.

For low-frequency $(20 \mathrm{~Hz})$ fatigue testing, a newly developed electrohydraulic material test system, MTS ${ }^{\oplus} 810$, was used. This system was equipped with an advanced CENTORR/VI TESTORR $^{\mathrm{TM}}$ furnace, such that tests could be conducted in different environments, including air, vacuum, argon, etc. The high-vacuum environment was obtained by first using a mechanical pump to obtain a rough vacuum, and then the furnace was evacuated with a diffusion pump to reach $10^{-6}$ to $10^{-7}$ torr vacuum within a few hours.
For high-frequency $(1,000 \mathrm{~Hz})$ fatigue testing, a state-of-the-art material test system, MTS ${ }^{\circledR} 8101,000 \mathrm{~Hz}$, was employed. This material test system had a Teststar II controller ${ }^{(3)}$ and operation software. It had high-speed and accurate data acquisition capabilities. The "voice coil" servovalve enabled the material test system to conduct tests at $1,000 \mathrm{~Hz}$. This high-frequency material test system provided the capabilities to conduct the fatigue test under accurate control and complete a fatigue test of life up to $10^{9}$ cycles with in a reasonable time period (11 days).

High-cycle fatigue tests were performed under load control using a sinusoidal waveform at $20 \mathrm{~Hz}$ and $1,000 \mathrm{~Hz}$. Loading was from tension to tension, with an R-ratio of 0.05 , and in different environments, i.e., regular air, dry air, and vacuum. All tests were conducted at ambient temperature $\left(25^{\circ} \mathrm{C}\right)$. The specimens were cyclically loaded until failure or up to approximately $10^{7}$ cycles as run-out for $20 \mathrm{~Hz}$ test, up to $10^{9}$ cycles as run-out for $1,000 \mathrm{~Hz}$ test.

\section{Microstructural Characterization}

The as-received and tested specimens were subjected to detailed microstructural characterizations using X-ray diffraction, OM, SEM, and TEM, and SEM for fractography.

The metallographic specimens prepared for the OM and SEM observations were mechanically polished according to standard procedures. Prior to etching, the mechanically-polished specimens were electropolished. A solution of $730 \mathrm{ml}$ ethanol, $78 \mathrm{ml}$ perchloric, $90 \mathrm{ml}$ distilled water, and $100 \mathrm{ml}$ butylcellosolve was used for electropolishing. The mechanically-polished specimens were placed on a Buehler Electromet ${ }^{\mathbb{Q}} 4$ Polisher/Etcher at a direct current (DC) potential of 20 volts with a stainless steel cathode for 5 to 10 seconds in order to remove the mechanically-deformed surface by electropolishing.

For etching, a solution composed of $95 \mathrm{ml}$ of reagent grade hydrochloric acid $(\mathrm{HCl})$ and 5 gram oxalic acid powder was used. The specimen was contacted with a stainless steel probe as the anode. A graphite rod was used as the cathode, and it was placed in the electrolyte near the specimen. Etching was conducted at a DC potential of 1 volt for 5 to 10 seconds.

The specimens for the TEM study were sliced $0.1 \mathrm{~mm}$ thick and 3 $\mathrm{mm}$ diameter, and then mechanically polished. They were electropolished by a Struers Tenupol-3 electrolytic polishing apparatus at a DC potential of 20 volts, using the solution mentioned above.

\section{$\underline{\text { Temperature Measurement }}$}

In the present study, an advanced, high-speed, and high-sensitivity Raytheon Radiance $\mathrm{HS}^{\circledR}$ infrared (IR) imaging system was used to record the temperature changes during high-cycle fatigue. The IR thermography is the process of detecting the invisible infrared radiation and converting the energy detected into visible light. The resultant image depicts and quantifies the energy being radiated and reflected from the object viewed, and can be transformed into temperature maps. IR thermography is a convenient technique for developing digital temperature maps from the invisible radiant energy emitted from stationary or moving objects at any distance. There is no surface contact or any perturbation of the actual surface temperature of the objects investigated. 
The IR camera employed had a $256 \times 256$ pixels focal-plane-array (FPA) InSb detector, and was sensitive to $3-5 \mu \mathrm{m}$ wavelength thermal radiation. The camera operates in a snapshot mode at a frequency up to $144 \mathrm{~Hz}$, and can be externally triggered. The temperature resolution of the camera is $0.015^{\circ} \mathrm{C}$ at $23^{\circ} \mathrm{C}$. Before fatigue testing, a thin submicroscopic graphite coating was applied to the specimen in order to reduce IR reflections. The temperature measurement of the IR camera was calibrated by a thermocouple, and the relationship of IR radiant-energy intensity and temperature was established by a best-fit line of the measured results.

\section{$\underline{\text { Results and Discussion }}$}

\section{High-Cycle Fatigue Stress-Life Data}

The stress vs. fatigue life in terms of number of cycles to failure or run-out (S-N) curves, including $20 \mathrm{~Hz}$ in regular air, dry air, and vacuum, and $1,000 \mathrm{~Hz}$ in regular air, are shown in Figure 2. The regular air environment contained the typical content of about $20 \%$ oxygen and $80 \%$ nitrogen (volume percent). In the laboratory, the relative humidity of the regular air was $20 \%$ to $26 \%$. The test environment of dry air contained the same amount of oxygen and nitrogen but with $0 \%$ relative humidity. For the vacuum environment, the amount of oxygen and moisture was negligible under the vacuum of $10^{-6}$ to $10^{-7}$ torr.

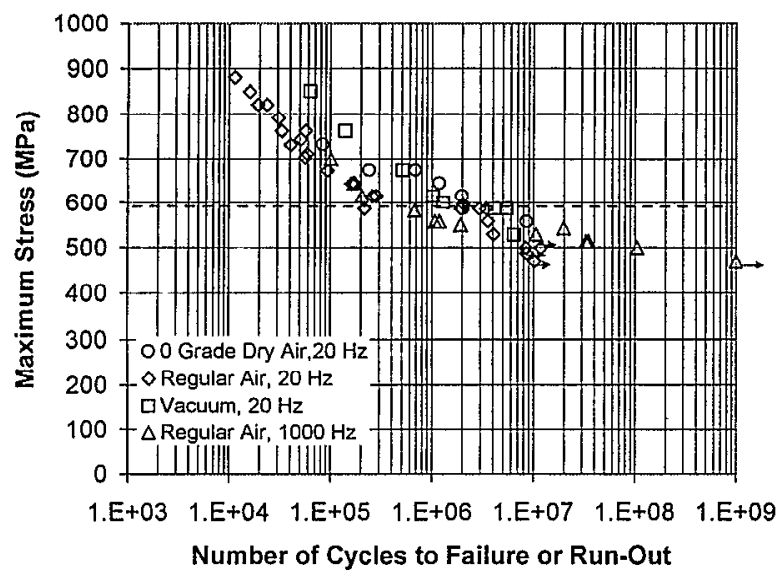

Figure 2: High-Cycle Fatiguc Testing Results, S-N Data, of ULTIMET Alloy. Note That the Arrow Indicates a Run-Out without Failure, and the Dashed Line Represents the Applied Maximum Stress of the Plateau Region.

The general trend of the S-N data was that the fatigue life increased with decreasing maximum stress level, as is normally observed. As can be seen from Figure 2, the fatigue life in vacuum environment at $20 \mathrm{~Hz}$ was much longer than that in the regular air environment at $20 \mathrm{~Hz}$. Generally, the fatigue life in the vacuum environment was 4 times greater than that in the regular air environment. It can also be noticed that the fatigue life in dry air at $20 \mathrm{~Hz}$ was longer than that in the regular air. This trend indicates that the fatigue life of the ULTIMET alloy was greatly affected by the oxygen and moisture in the environment.

It has been generally found that there is a great increase in temperature at high-frequency, $1,000 \mathrm{~Hz} \cdot{ }^{[10-13]}$ In the present study, the temperature increase was measured by an advanced IR camera. Depended on the stress level, at low frequency, $20 \mathrm{~Hz}$, it was about 0 to $60^{\circ} \mathrm{C}$. At high frequency, $1,000 \mathrm{~Hz}$, it was about 0 to $400^{\circ} \mathrm{C}$. As shown in Figure 2, within the experimental error, the S-N curves of 20 and $1,000 \mathrm{~Hz}$ in the regular air environment were in reasonably good agreement. Specifically, at the applied maximum stress level above $600 \mathrm{MPa}$, the test results at 20 and $1,000 \mathrm{~Hz}$ in the regular air environment grouped together. However, at the applied maximum stress level below $600 \mathrm{MPa}$, but above $530 \mathrm{MPa}$, the fatigue life at $20 \mathrm{~Hz}$ was greater than that at $1,000 \mathrm{~Hz}$. At the applied maximum stress level below $530 \mathrm{MPa}$, the fatigue life at $1,000 \mathrm{~Hz}$ was longer than that at $20 \mathrm{~Hz}$

Regardless of the testing frequencies and environments employed, there was a plateau region on the S-N curve. For the $20 \mathrm{~Hz}$ fatigue test results, the maximum stress level at the plateau region was near the yield strength of $586 \mathrm{MPa}$, and slightly higher than that at $1,000 \mathrm{~Hz}, 540 \mathrm{MPa}$. For the tests in dry air environment, there was another plateau region, which was at $670 \mathrm{MPa}$.

It is likely that the plateau region was due to the phase transformation induced by the plastic deformation. The shift of the plateau region with testing frequencies might be explained by temperature rises, which accelerated the phase transformation. The presence of oxygen and moisture in the testing environment was found to be harmful to the high-cycle fatigue properties of the ULTIMET alloy.

\section{Microstructure Characterization}

Figures 3 and 4 show the microstructure of ULTIMET alloy in the as-received, solution-annealed condition. The microstructure consisted essentially of a single FCC phase with a large number of annealing twins, and the grain size varied from 50 to $250 \mu \mathrm{m}$, with an average of approximately $80 \mu \mathrm{m}$ as shown in Figure 3. The high-magnification SEM micrographs in Figure 4 show the Widmanstatten-type morphology, which is more clearly represented in the back-scattered-electron image, Figure 4(a), than the secondary-electron image, Figure 4(b). The single-phase, FCC, characteristic of ULTIMET alloy was also confirmed by the X-ray diffraction analysis, ${ }^{[14]}$ which indicated that the amount of secondary phase, HCP, was very small or not present.

ULTIMET alloy has a low stacking fault energy (SFE). The stacking faults were abundant in the as-received material, as evidenced in Figure 5(a) and confirmed by TEM in Figure 5(b). In the high-magnification TEM images shown in Figure $5(b)$, the characteristic features of stacking faults, which were created by the movement of partial dislocations, are very clear. In fact, the Widmanstatten structure in Figure 4 and Figure 5(a) were composed of these stacking faults. The stacking faults were uniformly scattered in each grain.

It has been observed that twinning contributes significantly to the plastic deformation of low SFE metals at relatively large strains (about $10 \%$ ), ${ }^{[15]}$ Formation of the HCP phase or FCC twins of macroscopic size may be considered as a nucleation and growth process. The transformation of FCC to HCP can be achieved by the passage of a partial dislocation on every second $\{111\}$ plane in an FCC crystal, i.e. transforming $A B C A B C$ to $A B A B A B$, where $A, B$, and $C$ are the stacking sequences of an FCC crystal. While the passage of a partial dislocation on every adjacent $\{111\}$ plane results in the formation of an FCC twin, i.e. transforming $A B C A B C$ to $A C B A C B$. Once the $H C P$ phase or FCC twin embryo is formed by dislocation interactions, it may then thicken 
by overlapping of other nuclei formed on the $\{111\}$ planes parallel to its habit planes. Dislocation density is an important factor for the formation of the HCP phase and FCC twins.

For the high-cycle fatigue tests of ULTIMET alloy, the strain was relatively small (less than $5 \%$ ), and the important microstructural feature observed was the development of abundant stacking faults. The interaction of the stacking faults may form the FCC twins and/or HCP phase. As presented in Figure 6, the stacking faults formed a crisscrossed network over the entire deformed area in the gage section.

The dark-field image of Figure 7(a) exhibited the FCC twins oriented in the 10 o'clock direction which contributed to the "a" Bragg reflection of Figure 7(d). The bright FCC twins along the 2 o'clock direction of Figure 7(b) provided the contribution of "b" Bragg reflection of Figure 7(d). In the bright-field image, Figure $7(\mathrm{c})$, the dislocation structure was lying along directions and planes corresponding to the easy glide systems $\{111\}\langle 110\rangle$. Apparently, during fatigue, the interaction of the great amount of stacking faults formed FCC twins and had strong influence on the fatigue behavior of ULTIMET alloy.

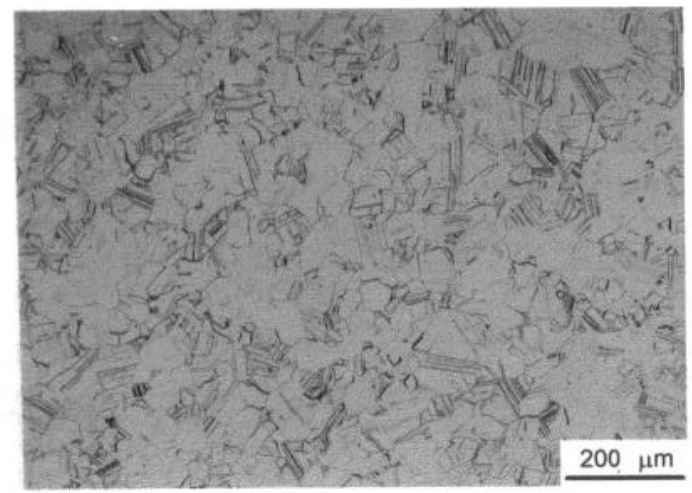

Figure 3: Optical Micrograph Showing the Characteristic Microstructure of ULTIMET Alloy.

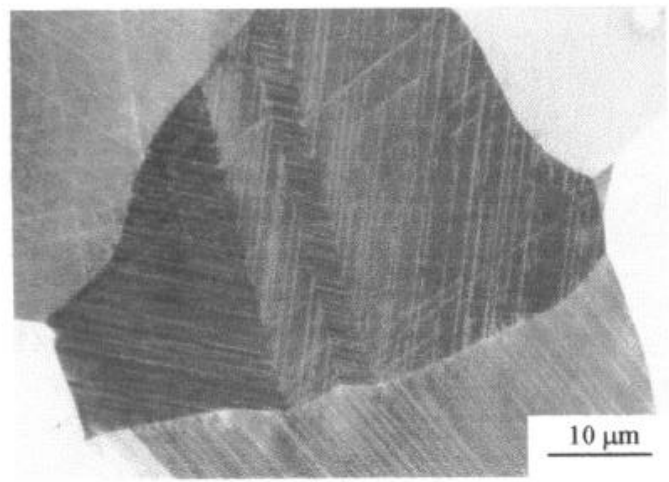

(a)
After specimen failed, one broken half was sectioned in the longitudinal direction and mechanically- and electro-polished. As shown in Figure 8(a), below the fracture surface, there was a secondary crack. In the high-magnification SEM back-scatteredelectron image 8 (b), at the area around the tip of the secondary crack in Figure 8(a), there were a large number of microvoids which were aligned along the twin boundaries. It is suspected that the linkage of these microvoids may have created the macrocrack.

The stacking faults were found to play an important role in the fatigue process of ULTIMET alloy. As fatigue progressed, the stacking faults tended to form a network structure, and the density and thickness of stacking faults increased. The large number of stacking faults formed in the material could also serve as nuclei for the FCC-HCP transformation. Although the HCP phase was not found in the as-received and fatigue-fractured specimens examined, it is suspected that the phase transformation may have occurred in the region close the fracture surface. Microvoids formed along the interface of twins where deformation triggered slip systems on both sides of the interface. The linkage of the microvoids eventually led to the formation of the crack which caused the failure of the material.

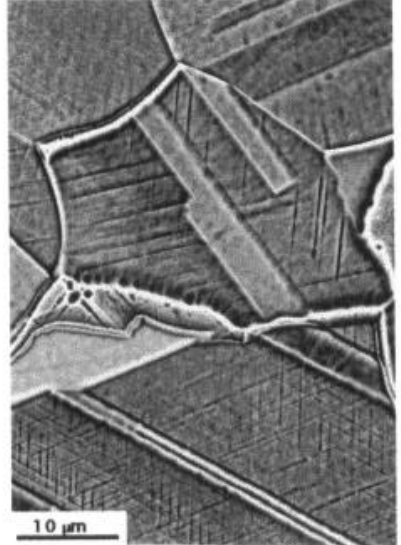

(a)

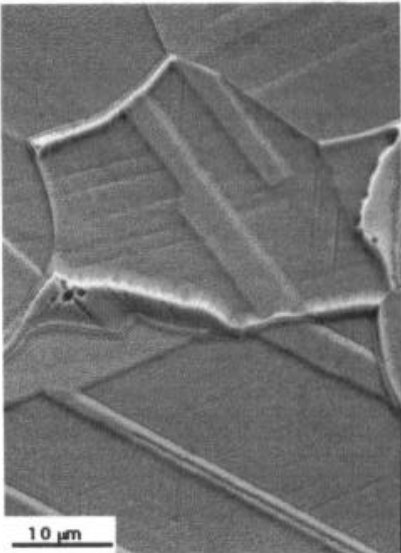

(b)
Figure 4: SEM Micrographs Showing the Widmanstaten-Pattern in the Grains: (a) Back-Scattered Electron Image and (b) Secondary-Electron Image.

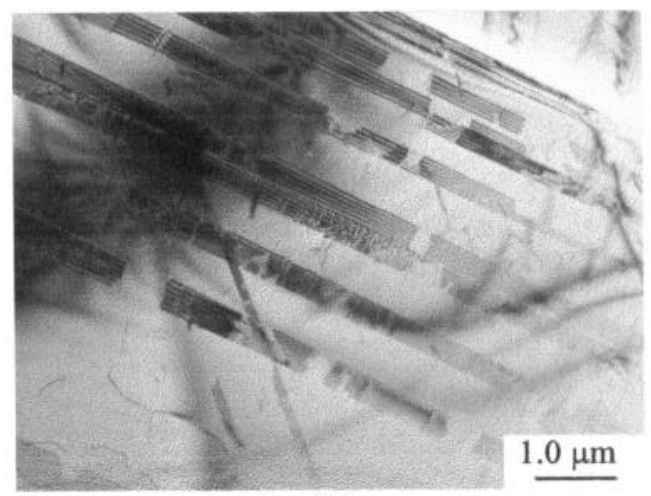

(b)

Figure 5: Abundant Stacking Faults of ULTIMET Alloy in the As-Received Condition: (a) SEM Back-Scattered-Electron Image and (b) High-Magnification TEM Image. 


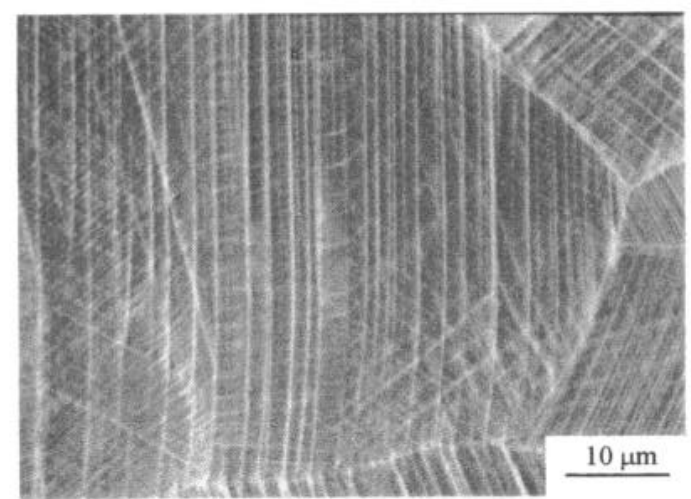

(a)

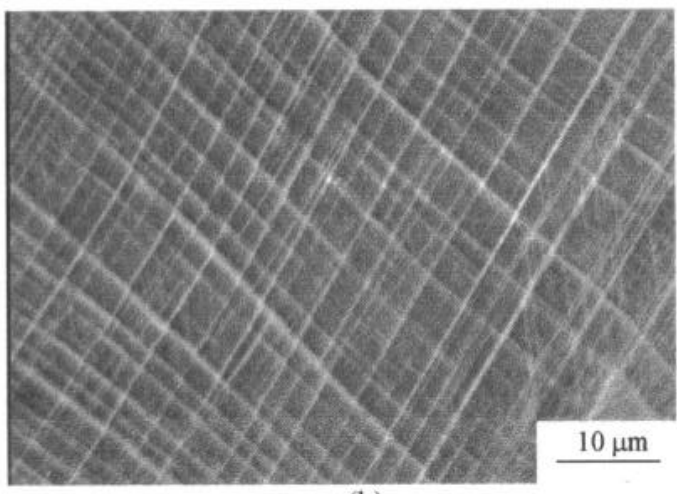

(b)

Figure 6: Abundant Stacking Faults of ULTIMET Alloy in the Cyclically-Deformed Condition: (a) Fatigue Tested at the Maximum Stress Level of $586 \mathrm{MPa}$, (b) Fatigue Tested at the Maximum Stress Level of $703 \mathrm{MPa}$.

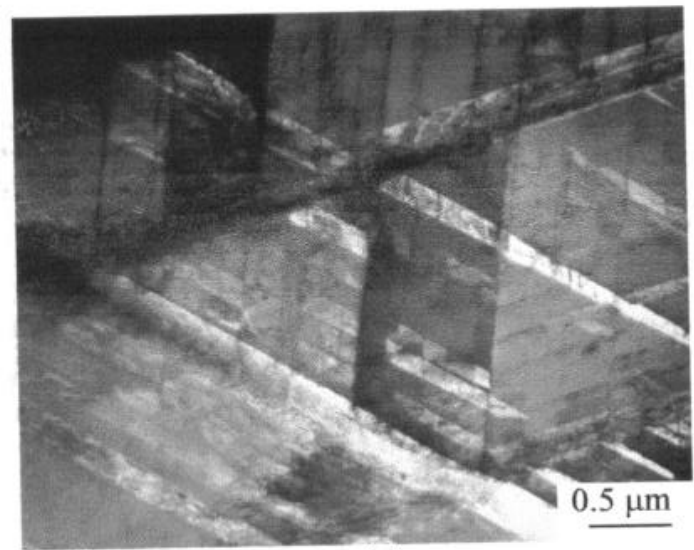

(a)

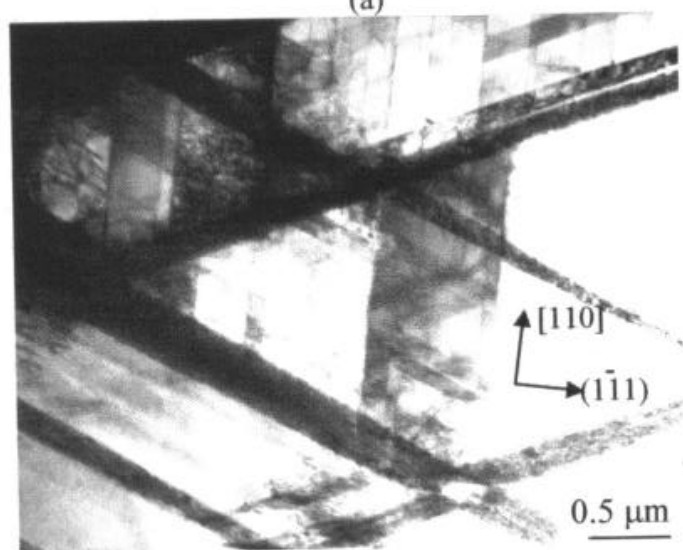

(c)

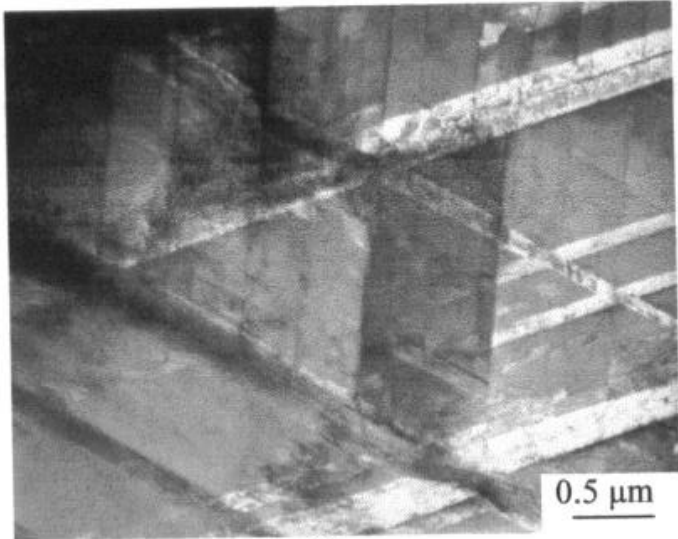

(b)
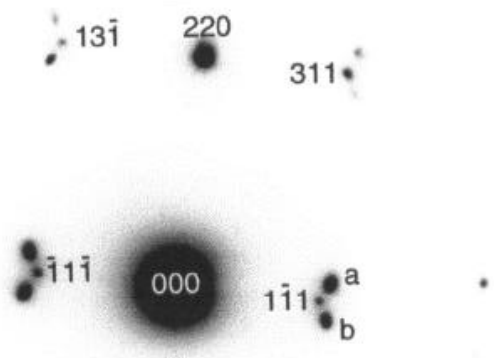

•

(d)

Figure 7: TEM Micrographs of ULTIMET Alloy in the Fatigue-Fractured Condition Showing FCC Twins: (a) Dark Field Image of One Set of FCC Twins Contributing to Bragg Reflection "a" in Figure 7(d), (b) Dark Field Image of Another Set of FCC Twins Contributing to Bragg Reflection "b" in Figure 7(d), (c) Bright Field, and (d) diffraction Pattern from Figure 7(c).

\section{Fractography}

The fracture surfaces of the failed specimens were examined by SEM. Figure 9 presents the fracture surface of a specimen fatigued at a relatively high applied maximum stress of 821 $\mathrm{MPa}$, with an R-ratio of 0.05 , in air and at room temperature. The topography of the fracture surface was uneven and possessed very crystallographic features as shown in Figure 9(a). The crack-initiation sites were identified by tracing back along the fracture-surface markings, which radiated from the point of origin. There were five fatigue-crack-initiation sites, as indicated by circles, and all of them were at the specimen surface. A representative high-magnification micrograph of the initiation sites presented in Figure 9(b) reveals a cleavage-like 
fracture surface typical of stage I crack initiation. The size of the crack-initiation sites was on the order of the grain size, ranging from 100 to $200 \mu \mathrm{m}$. At a lower applied maximum stress levels, the fracture surface showed the same appearance, but there were fewer crack-initiation sites.

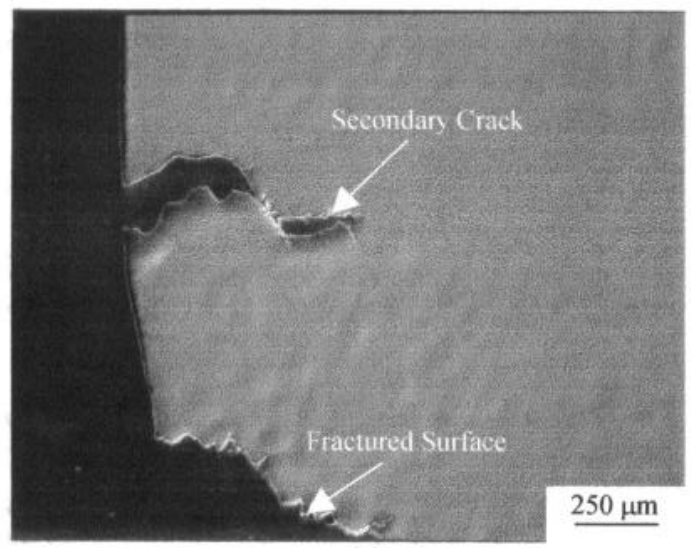

(a)
After the crack-initiation stage, the cracks propagated through the gage section of the specimen. The characteristic feature of the crack-propagation region was the "stair step" appearance, as revealed by SEM examination in Figure 9(c). This trend indicated that the crack propagation was very crystallographic. In previous work, Shen et al. ${ }^{[16]}$ pointed out that the striation spacing was small, and the propagation speed was slow.

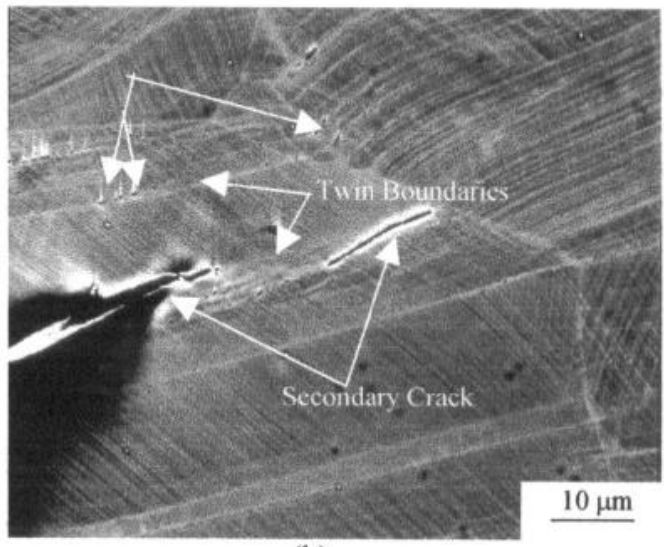

(b)

Figure 8: SEM Micrographs of ULTIMET Alloy in the Fatigue-Fractured Condition (a) Secondary-Electron Image Showing the Fracture Surface and Secondary Crack, (b) Back-Scattered-Electron Image Showing the Microvoids around the Tip of a Secondary Crack in Figure 8(a) and Their Linkage to Form a Crack.

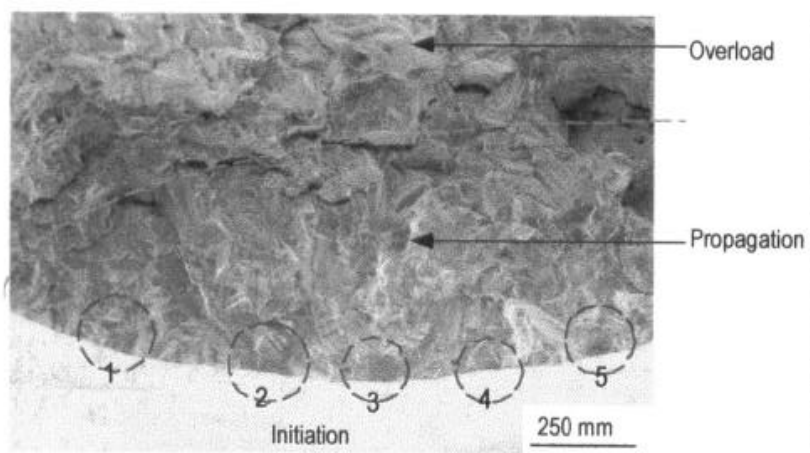

(a)

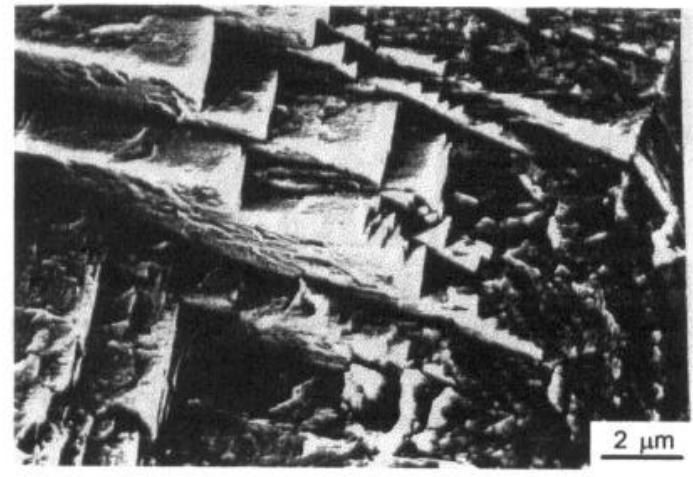

(c)

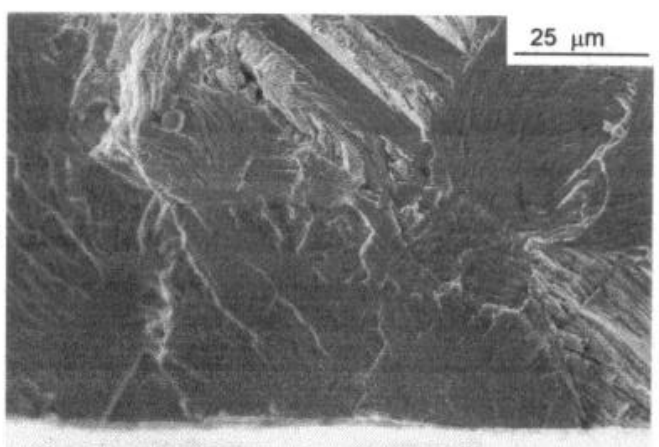

(b)

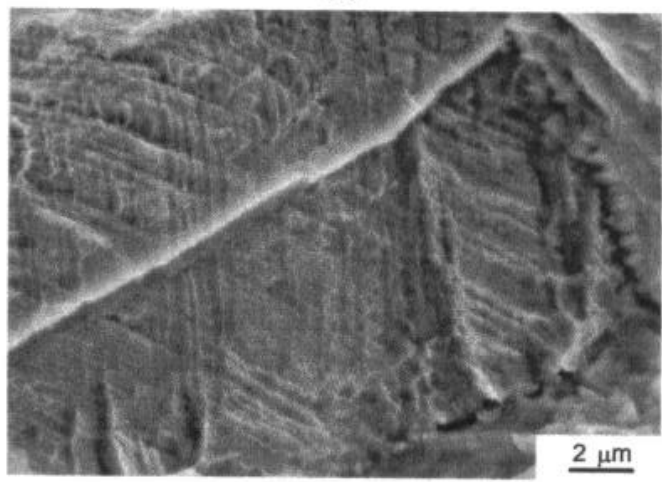

(d)

Figure 9: SEM Fractographs of a Fatigue-Fractured Specimen: (a) Overview of the Fractured Surface and the Crack-Initiation Sites Noted by the Circles with Numbers, (b) SEM Fractograph of the Initiation Site 2 from Figure 9(a), (c) 'Stair Step' Feature of the CrackPropagation Region, and (d) Dimpled Fracture Surface of the Final Overload Region. $\left(\sigma_{\max }=821 \mathrm{MPa}, \mathrm{R}=0.05\right.$, Room Temperature, in Regular Air, Fatigue Life of 23,568 Cycles, $20 \mathrm{~Hz}$ ) 


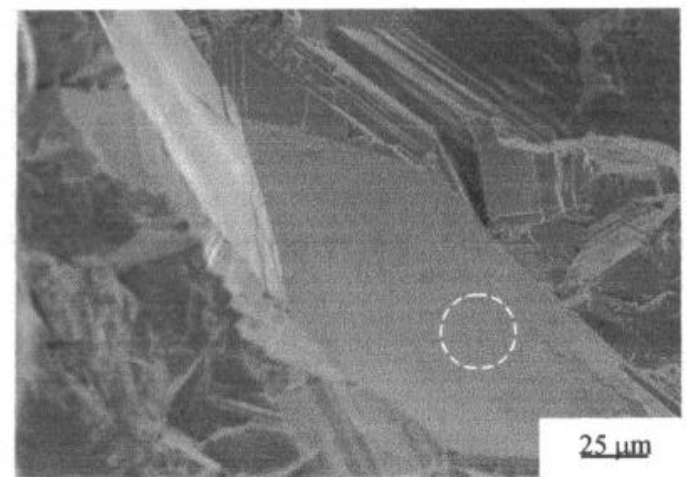

(a)

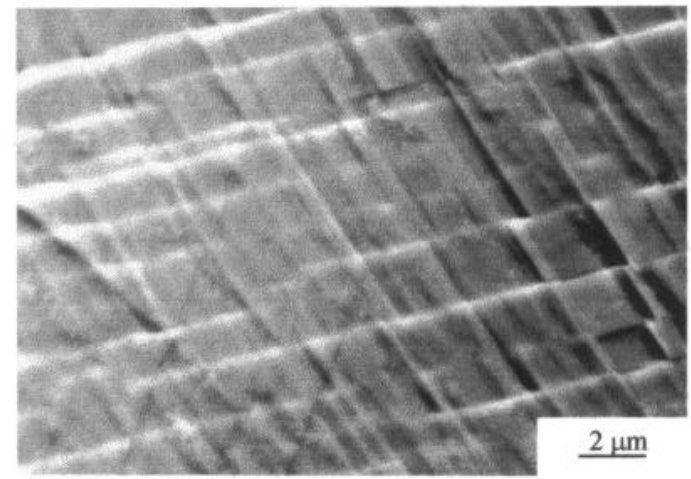

(b)

Figure 10: SEM Fractographs of a Fatigue-Fractured Specimen: (a) Crack-Initiation Site, (b) High-Magnification Micrograph from the Circled Region in Figure 10(a). $\left(\sigma_{\max }=674 \mathrm{MPa}, \mathrm{R}=0.05\right.$, Room Temperature, in Dry Air, Fatigue Life of $\left.695,280 \mathrm{Cycles}, 20 \mathrm{~Hz}\right)$

The fractograph shown in Figure 9(d) illustrates the final overload region. The features were similar to that of a typical tensile overload. Interestingly, the regularity of the microstructure of the fracture surface in Figure 9(d) is consistent with the networked stacking-faults structure in Figures 6 and 7.

The SEM micrographs in Figure 10 show the crack-initiation site of a specimen fatigue tested at $20 \mathrm{~Hz}$ with an applied maximum stress of $674 \mathrm{MPa}$ in the dry air. The fatigue crack initiated from an internal origin of the specimen, as shown in Figure 10(a), but it possessed the same feature as the crack-initiation site in Figure 9(b). The high-magnification view of the cleavage-like crackinitiation site, Figure 10(b), shows the presence of slip bands. The structure of the slip bands on the crack-initiation site is consistent with the networked stacking-faults structure shown in Figure 6. This feature also provided the evidence that the crack may initiate from the interface of twins which experienced large plastic deformation during fatigue, as shown in Figure 8(b).

Under all conditions, the high-cycle fatigue behavior of ULTIMET alloy exhibited a typical two-stage fatigue-crackgrowth process: (a) stage I fatigue-crack initiation in which the cracks formed on those planes most closely aligned with the maximum shear-stress direction in the grains of the fatigue specimen, and (b) stage II fatigue-crack growth in which the maximum principal tensile stress controlled crack propagation in the region of the crack tip. It was noted that the stage I crack was confined within one grain and the fracture appearance was cleavage-like. Generally, for the crack initiation from the surface, as shown in Fig. 9(b), the persistent slip bands on the surface led to the stage I crack propagation, but for the crack initiation from the internal origin, as presented in Figure 10, the crack initiation resulted from the evolution of the stacking faults.

\section{$\underline{\text { Crack-Initiation Location }}$}

Typically, the fatigue-crack initiation occurs on the specimen surface as a result of the irreversible process of extrusion and intrusion formation through slip deformation. However this was not generally true for the fatigue-crack initiation of ULTIMET alloy. The crack-initiation site was found to vary from surface to subsurface depending on test variables. Figure 11 summarizes the fatigue-crack-initiation sites observed under various testing conditions of frequency and environment. In the regular air environment, for the lower-frequency $(20 \mathrm{~Hz})$ high-cycle fatigue at higher applied maximum stress levels greater than $600 \mathrm{MPa}$, the fatigue cracks initiated from the surface, as shown in Figure 9(b). However, at peak stresses lower than $600 \mathrm{MPa}$, corresponding to the plateau region, subsurface or near surface crack initiation was observed. This can be seen from Figure 12(a), for a peak stress of $586 \mathrm{MPa}$. The crack-initiation sites presented in Figures 12(b) and (c) indicate that the cleavage-like features were retained.

Similarly, in the regular air environment, for the high-frequency $(1,000 \mathrm{~Hz})$ high-cycle fatigue tests at the applied maximum stress levels greater than $600 \mathrm{MPa}$, the fatigue cracks initiated at the surface. For the applied maximum stress levels below $600 \mathrm{MPa}$ the fatigue cracks initiated from the subsurface.

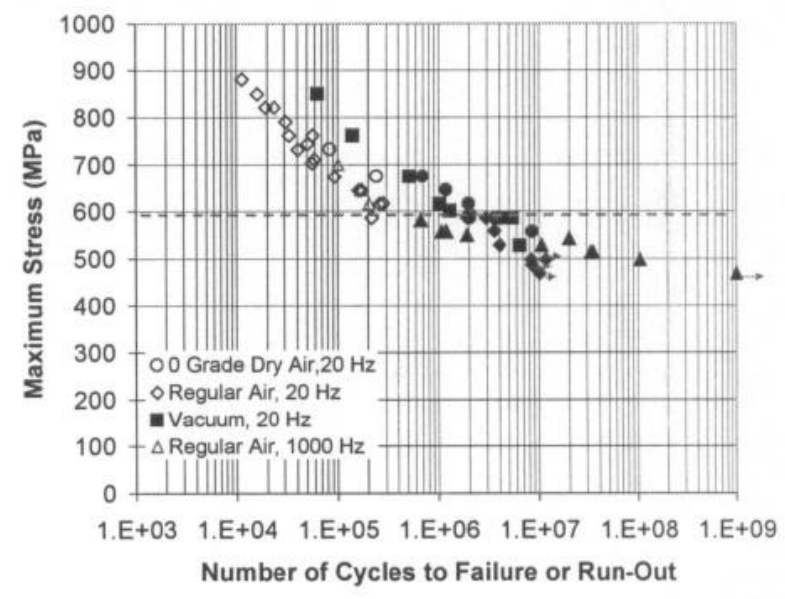

Figure 11: High-Cycle Fatigue Testing Results, S-N Data, of ULTIMET Alloy. Note That the Opened Symbol Represents the Fatigue Crack Initiated from the Surface, the Solid Symbol Stands for the Fatigue Crack Initiated from the Subsurface, the Arrow Indicates a Run-Out without Failure, and the Dashed Line Represents the Applied Maximum Stress of a Plateau Region.

For tests conducted in the dry-air environment, fatigue cracks initiated at the surface when the applied maximum stress levels were greater than $674 \mathrm{MPa}$. At stress levels below $674 \mathrm{MPa}$, the fatigue cracks originated from the subsurface, as exhibited in Figure 10. In the vacuum environment, all the cracks initiated at 
subsurface locations regardless of the maximum applied stress level at the test frequency of $20 \mathrm{~Hz}$.

For both surface and subsurface crack initiation, the common features of the crack-initiation sites were: (a) flat facets with the size on the order of 100 to $200 \mu \mathrm{m}$ at the origin, (b) the absence of precipitates or inclusions. All of the fracture surfaces examined retained a crystallographic appearance, and the initiation sites exhibited the cleavage-like feature.

Internal fatigue-crack-initiation origins have been attributed to the presence of inclusions in some materials. ${ }^{[17]}$ In ULTIMET alloy, no inclusions were observed to cause crack initiation. Careful investigation of the material by SEM showed that it was very clean. It has been reported that in the titanium alloy system, e.g., $\mathrm{Ti}-6 \mathrm{Al}-4 \mathrm{~V},{ }^{[17-19]}$ and stainless steel system, such as a typical martensitic stainless steel, ${ }^{[18]}$ the crack-initiation site changed from the surface to subsurface in specimens undergoing highcycle fatigue subjected to either low peak stresses or long fatigue lives.

The fatigue-crack-initiation site was found to be dependent on the environmental conditions. All of the specimens tested in vacuum experienced subsurface crack initiation. For specimens tested in dry air, the fatigue cracks started to form internally at a higher applied maximum stress levels than that of the regular air.
For the specimens in the as-received condition, all surfaces were mechanically polished. Therefore, the surface was harder than the interior of the specimen. At high applied stresses, the surface was more susceptible to damage from oxygen and moisture, and surface crack initiation was favored. At low applied stresses, the harmful effects of oxygen and moisture were reduced because fewer slip bands were formed, and internal crack initiation was favored. At $1,000 \mathrm{~Hz}$, this effect was not as pronounced. The change of the crack-initiation site from the surface to subsurface might also help to explain the occurrence of the plateau.

Another reason for the presence of the plateau region might be related to the FCC to $\mathrm{HCP}$ phase transformation induced by plastic deformation. All of the tests conducted in air at $20 \mathrm{~Hz}$ had the same plateau region at the applied maximum stress level of $600 \mathrm{MPa}$. The plateau region for the high-frequency fatigue tests in air shifted down to $540 \mathrm{MPa}$. This change was probably due to the fact that the specimens tested at $1,000 \mathrm{~Hz}$ experienced a higher temperature rise than those tested at $20 \mathrm{~Hz}$. Further work is planned to gain a better understanding of the plateau region by conducting strain-controlled tests at room and elevated temperatures.

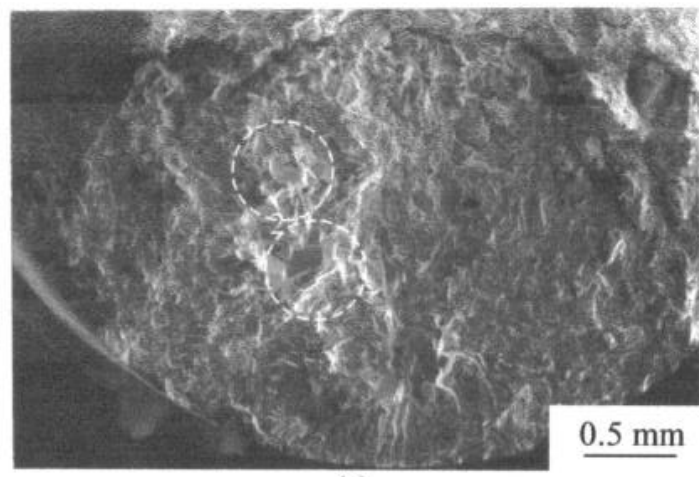

(a)

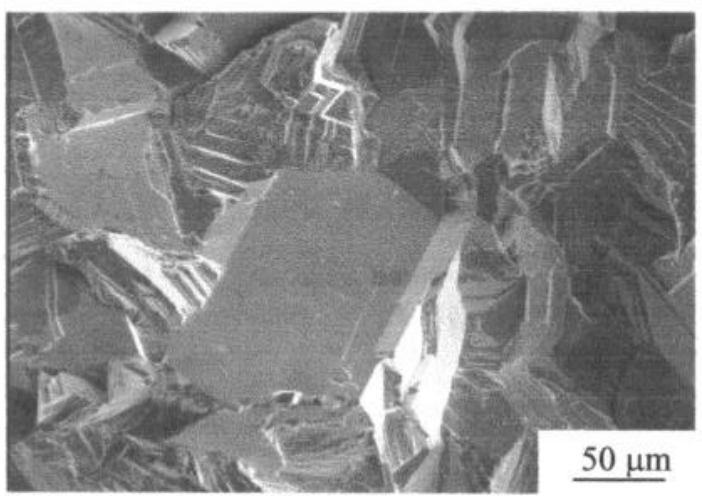

(b)

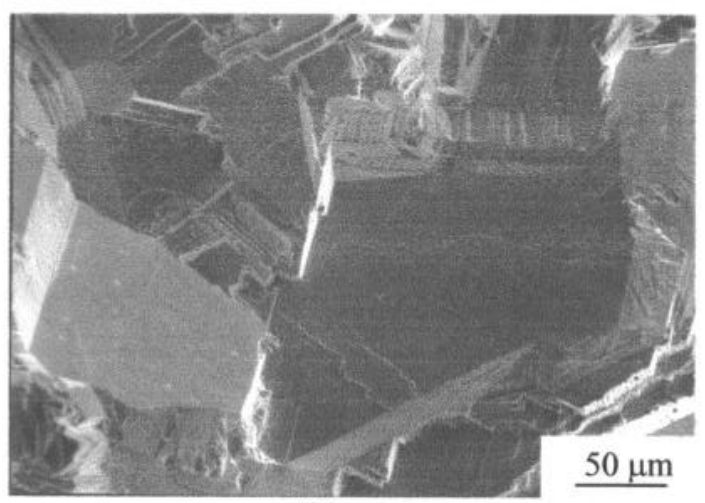

(c)

Figure 12: SEM Fractographs of a Fatigue-Fractured Specimen: (a) Overview of the Fractured Surface and the Crack-Initiation Sites Noted by the Circles with Numbers, (b) SEM Fractograph of the Initiation Site 1 from Figure 12(a), and (c) SEM Fractograph of the Initiation Site 2 from Figure 12(a). $\left(\sigma_{\max }=586 \mathrm{MPa}, \mathrm{R}=0.05\right.$, Room Temperature, in Regular Air, Fatigue Life of 2,941,100 Cycles, $20 \mathrm{~Hz}$ ) 


\section{Conclusions}

1) High-cycle fatigue data were developed for the ULTIMET alloy. The fatigue lives decreased as the applied maximum stress levels increased, as is normally observed. The high-frequency $(1,000 \mathrm{~Hz})$ high-cycle fatigue tests gave results comparable to the low-frequency $(20 \mathrm{~Hz})$ tests.

2) Moisture and oxygen were found to have significant detrimental effects on the fatigue lives. The absence of moisture and/or oxygen increased fatigue life.

3) Plateaus were found in all of the $\mathrm{S}-\mathrm{N}$ curves. For tests at $20 \mathrm{~Hz}$, the plateau occurred at an applied maximum stress level near the yield strength of the alloy, $596 \mathrm{MPa}$. For tests at $1,000 \mathrm{~Hz}$, the plateau occurred at a maximum stress level of $540 \mathrm{MPa}$. It is likely that the plateau region was due to the FCC to HCP phase transformation induced by the plastic deformation and the change of the crack-initiation site from the surface to subsurface.

4) The microstructural characterization of the test specimens revealed that the evolution of stacking faults is a key fatiguedamage process. Stacking faults were formed in a network structure. The number of stacking faults increased as cycling progressed.

5) The fractographic studies showed that there was a change in the crack-initiation site from the surface to subsurface, depending on the applied maximum stress level and environment. The presence of oxygen and moisture tended to promote crack initiation at the surface. The change of the crack-initiation site from the surface to subsurface was associated with a long fatigue life.

6) Regardless of the crack origin, the fracture surface at the crackinitiation site was cleavage-like, and its size was on the order of the grain size, $100 \mu \mathrm{m}$ to $200 \mu \mathrm{m}$. The crack-propagation fracture surface was crystallographic in nature.

\section{Acknowledgements}

This work is supported by the Haynes International, Inc. We also acknowledge the financial support of the National Science Foundation, the Division of Design, Manufacture, and Industrial Innovation, under Grant No. DMI-9724476, and the Combined Research-Curriculum Development Program, under EEC9527527, to the University of Tennessee, Knoxville, with Dr. Delcie R. Durham and Ms. Mary Poats as program managers, respectively. We appreciate the financial support of the Center for Materials Processing and Office of Research Administration at the University of Tennessee, Knoxville. The great help of Dr. H. Wang, from Oak Ridge National Laboratory on the temperature measurements during high-cycle fatigue testing, is highly appreciated. Many thanks are due to Mr. Doug Fielden, Mr. Greg Jones, and Mr. Larry Smith at the University of Tennessee for their great help in setting up the electrohydraulic machines and excellent technical support.

\section{$\underline{\text { References }}$}

1. D. L. Klarstrom, "Wrought Cobalt-Base Superalloys," Journal of Materials Engineering and Performance, No. 2, 1993, pp. 523530.
2. P. Crook and D. L. Klarstrom, "Advances in Alloy Design for Aggressive Wear Service," ADVMAT' 91, San Diego, CA, June 1991.

3. P. Crook and A. V. Levy, "Cobalt-Base Alloys," Metal Handbook Vol. 18, 1992, pp. 766-771.

4. A. V. Levy and P. Crook, "The Erosion Properties of Alloys for the Chemical Processing Industries," Wear, Vol. 151, 1991, pp. 337-350.

5. H. M. Tawancy, V. R. Ishwar, and B. E. Lewis, "On the fcc-hcp Ttransformation in a Cobalt-Base Superalloy (HAYNES Alloy No. 25)," Journal of Materials Science Letter, Vol. 5, 1986, pp. 337-341.

6. Haynes International, ULTIMET ${ }^{(3)}$ Alloy, 1994, p. 3.

7. W. G. Moffatt, Binary Phase Diagrams Handbook, General Electric Company, 1976, p. 78.

8. H. Farhangi, R. W. Armstrong, and W. F. Regnault, "Transmission Electron Microscopy Detection of CyclicDeformation-Induced fcc to hcp Transformation in a Cobalt-Based Prosthetic Device Material," Materials Science and Engineering, Vol. 114, 1989, pp. 25-28.

9. ASTM Standard Practice (E466) for "Conducting Constant Amplitude Axial Fatigue Tests of Metallic Materials," 1995.

10. H. Wang, L. Jiang, P. K. Liaw, C. R. Brooks, and D. L. Klarstrom, "Infrared Temperature Mapping of UL,TIMET® Allny During High-Cycle Fatigue Tests," Metallurgical and Materials Transactions A Vol. 31A, 2000, pp.1307-1310.

11. P. K. Liaw, H. Wang, L. Jiang, B. Yang, J. Y. Huang, R. C. Kuo, and J. G. Huang, "Thermographic Detection of Fatigue Damage of Pressure Vessel Steels at $1,000 \mathrm{~Hz}$ and $20 \mathrm{~Hz}$," Scripta Metallurgica et Materiala, Vol. 40, 2000, pp. 389-395.

12. L. Jiang, H. Wang, P. K. Liaw, C. R. Brooks, and D. I.. Klarstrom, "Characterization of Temperature Evolution During High-Cycle Fatigue Tests, Part I, Experiments," submitted to Acta Metallurgica et Materialia.

13. L. Jiang, H. Wang, P. K. Liaw, C. R. Brooks, and D. L. Klarstrom, "Characterization of Temperature Evolution During High-Cycle Fatigue Tests, Part II, Modeling," submitted to Acta Metallurgica et Materialia.

14. L. Jiang, C. R. Brooks, P. K. Liaw, D. L. Klarstrom, and B. Muenchen "Phenomenological Aspects of the High-Cycle Fatigue of ULTIMET ${ }^{\text {B }}$ Alloy " to be submitted to Materials Science and Engineering.

15. S. Asgari, E. El-Danaf, S. R. Kalidindi, and R. D. Doherty, "Strain Hardening Regimes and Microstructural Evolution during Large Strain Compression of Low Stacking Fault Energy Fcc Alloys That Form Deformation Twins," Metallurgical and Materials Transactions A Vol. 28A, 1997, pp. 1781-1795.

16. E. Y. Shen, C. R. Brooks, P. K. Liaw, D. L. Klarstrom, and J. Y. Huang, "Fatigue Behavior of a Commercial Co-26Cr-9Ni (wt. \%) Basc Alloy (ULTIMET ${ }^{\circledR}$ )," High Cycle Fatigue of Structural Materials, Soboyejo, W. O. and Srivatsan, T. S., eds, TMS, 1997, pp. 313-326.

17. D. F. Neal and P. A. Blenkinsop, "Internal Fatigue Origins in $\alpha-\beta$ Titanium Alloy," Acta Metallurgica, Vol. 24, 1976, pp. 59-63. 18. A. Atrens, W. Hoffelner, T. W. Duerig, and J. E. Allison, "Subsurface Crack Initiation in High Cycle Fatigue in Ti6Al4V and in a Typical Martensitic Stainless Steel," Scripta Metallurgica, Vol. 17, 1983, pp. 601-606.

19. O. Umezawa and K. Ishikawa, "Phenomenological Aspects of Fatigue Life and Fatigue Crack Initiation in High Strength Alloys at Cryogentic Temperature," Materials Science and Engineering, Vol. A176, 1994, pp. 397-403. 